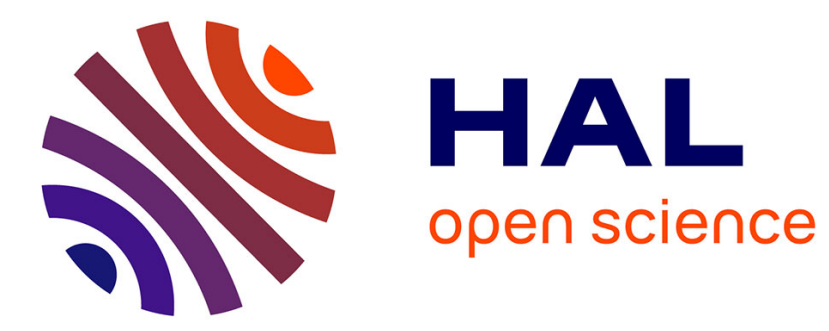

\title{
Can Small French Farms Provide an Opportunity for Employment in the Agricultural Sector?
}

\author{
Pauline Lécole
}

\section{To cite this version:}

Pauline Lécole. Can Small French Farms Provide an Opportunity for Employment in the Agricultural Sector?. EuroChoices, 2021, 20 (1), pp.48-54. 10.1111/1746-692X.12290 . hal-03053765

\section{HAL Id: hal-03053765 https://hal.inrae.fr/hal-03053765}

Submitted on 11 Dec 2020

HAL is a multi-disciplinary open access archive for the deposit and dissemination of scientific research documents, whether they are published or not. The documents may come from teaching and research institutions in France or abroad, or from public or private research centers.
L'archive ouverte pluridisciplinaire HAL, est destinée au dépôt et à la diffusion de documents scientifiques de niveau recherche, publiés ou non, émanant des établissements d'enseignement et de recherche français ou étrangers, des laboratoires publics ou privés. 


\title{
Can Small French Farms Provide an Opportunity for Employment in the Agricultural Sector?
}

\author{
Pauline Lecole
}

Creating or maintaining employment in European agriculture is a key issue. European decisionmakers tend to focus mainly on the employment potential of medium and large-scale farms, socalled professional farms. What about the potential of small farms, often qualified as 'nonprofessional farms' in the statistical jargon? What is the employment structure of these farms and how do they contribute to employment? Small farms have provided an employment refuge for workers who could not find enough work during the recent economic recession in Italy, Greece and Portugal (Salvioni et al., 2014). Should they be considered only during an economic recession?

Furthermore, in Europe and more particularly in France, small farms are no longer systematically associated with subsistence or semi-subsistence farms. Their image is undergoing a major change. Some appear innovative and capable of generating high valueadded activities. To what extent will these changes constitute employment opportunities in the French agricultural sector?

What role can public policies play in supporting small farms which create employment and, more broadly, how to support the development of the employment potential of small farms? The aim of this work is to encourage reflection on the adaptation or the development of public support measures, which would better take into account the specific features of labour-intensive small farms and/or would target specifically the creation and maintenance of jobs on small farms.

We first present the results of the literature on the value of supporting small farms, taking into account their contributions. Our analysis focuses on agricultural employment and is based on the case of small French farms. In order to better identify their contributions to employment, we study their employment structure and characterise small French farms that are labourintensive and those that are not. We conclude with public policy recommendations.

\section{Should public policies specifically support small farms?}

In the 1960s and 1970s, the Common Agricultural Policy (CAP) organised the structural adjustment of the agricultural sector. Small farms were considered to be unproductive and managed by older farmers unable to modernise. At that time, it was considered that they should be modernised or disappear (Müller, 1984). Today, it is well known that CAP aid is unevenly distributed among farmers and benefits larger structures. Recurrent criticisms have pointed out that almost 20 per cent of the largest CAP beneficiaries cumulate nearly 80 per cent of direct CAP aid. These figures have slightly changed during the various CAP reforms, particularly the 2014 reform. Yet, the distribution of aid per hectare, as well as the minimum thresholds for 
obtaining aid and transaction costs associated with applications, imply that the CAP provides little support to small farms (Lécole, 2017).

In France, for example, small farms received on average $€ 4,000$ of CAP support (1st and 2nd pillar) per agricultural work unit (AWU) compared to nearly $€ 13,000$ for medium-sized and large farms (Disar database, 2010).

Yet small farms are increasingly recognised as having a role in the provision of public goods that may justify specific support from public policies. The literature highlights the positive environmental externalities they supply, such as landscape diversity and biodiversity preservation, notably by maintaining agricultural activities in less favoured areas (Birol et al., 2006; Zasada, 2011). Moreover, and according to Winter et al. (2016), small farms also contribute to the maintenance of rural services, to the attractiveness of territories and to the maintenance of the population and thus of social infrastructures in remote areas.

There is, however, an important heterogeneity within small farms, which implies heterogeneity in their contributions. Lécole (2017) shows that some small farms also produce negative environmental externalities. For example, old and outdated equipment, lack of time or risk aversion in a situation of economic vulnerability may induce smallholders to increase pesticides use.

The heterogeneity of the contribution of small farms to employment has been insufficiently studied. We propose to analyse the structure of employment in small French farms. On the basis of this analysis, we will propose recommendations in terms of public policies to enhance the contribution of labour-intensive small farms and to facilitate the creation and maintenance of jobs in small farms.

\section{Characterisation of small French farms in 2010}

As discussed by Davidova (2014), many definitions of small farms exist. We identify small French farms as those with a standard output (SO) lower than $€ 25,000$. Standard output is a conventional indicator used to classify agricultural holdings by type of farming and by economic size.

This definition covers a large diversity of small farms. It includes farms with small areas dedicated to high value crops like market gardening but also structures with large areas dedicated to low value crops like grasslands in the case of extensive livestock farming.

The $€ 25,000$ threshold allows us to study the very small under-researched farms that are excluded from the database usually used to feed the reflections on the CAP, the Farm Accountancy Data Network (FADN).

In the French 2010 agricultural census, we counted 179,000 small farms, representing over one third of all farms in mainland France, covering almost 7 per cent of the total agricultural surface area and more than 13 per cent of the total agricultural work units. These farms had on average 
11 ha (the national average is $56 \mathrm{ha}$ ). A wide range of farms were represented but sheep, goats and beef cattle breeding farms dominated. An important particularity of small French farms was that farmers were 10 years older on average than those running medium and large farms. This can be explained by the high proportion of retired people among them (38 per cent as opposed to just over 2 per cent of medium and large farms).

Small French farms contributed more to employment per hectare of utilised agricultural area than large farms. The contribution per hectare was largely based on the labour provided by the farmer and was much higher than that of medium and large farms, as shown in Figure 1.

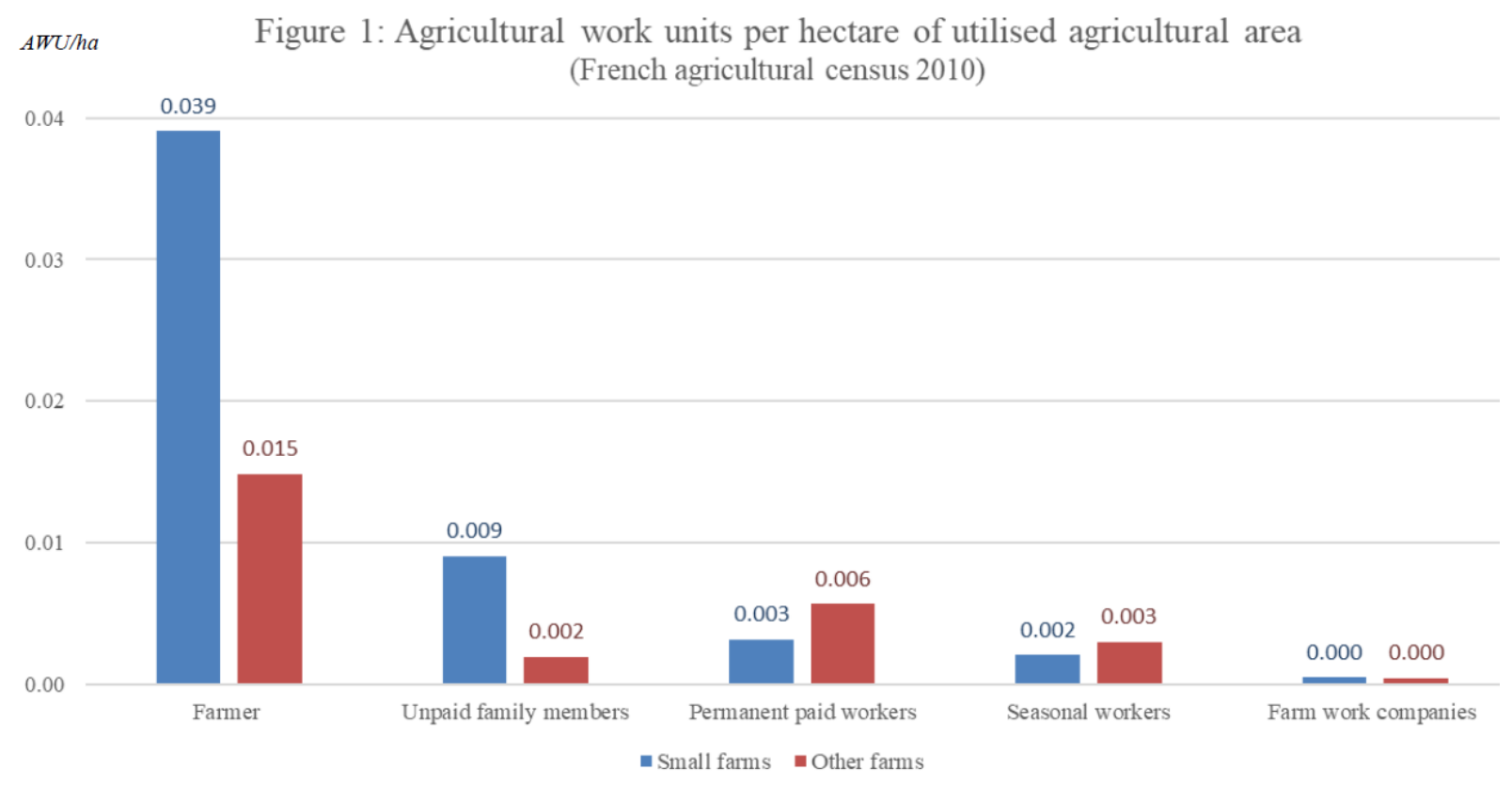

The important weight of family labour on small farms can also be highlighted. In a poor cash flow situation, one advantage of using family labour is that family workers do not have to be paid. A number of studies on small farms use this argument to explain their persistence (Hazell, 2005).

The contribution of paid workers per hectare was lower on small farms. Only 2 per cent of small farms employed permanent paid workers and 17 per cent hired seasonal workers. Small farm size, low income generation, lack of liquidity and poor access to the labour market can limit the size of the paid labour force on small farms. Moreover, the jobs offered by smallholders are very often part-time and therefore often unattractive.

\section{How was work allocated in small French farms?}

We call the combination of different types of work (unpaid family work, permanent family or non-family paid work, seasonal workers) a labour regime and propose a classification of small farms in eight different labour regimes. 
The labour regime is an efficient way to represent the allocation of labour on farms. It has been used in many modelling studies showing the effects of complementarities and/or substitution between different types of labour (Benjamin et al., 1996).

In order to limit the number of labour regimes, we decided not to include Farm Work Companies (FWCs). In most cases, they work for very occasional and specific tasks such as clearing plots, mulching or harvesting. However, we recognise cases of outsourcing of work through FWCs and present them in Box 1. Figure 2 shows each of these labour regimes and their share in the total population of small farms in France.

Figure 2: Labour regimes in small French farms and average agricultural work units by types of workforce (French agricultural census 2010)

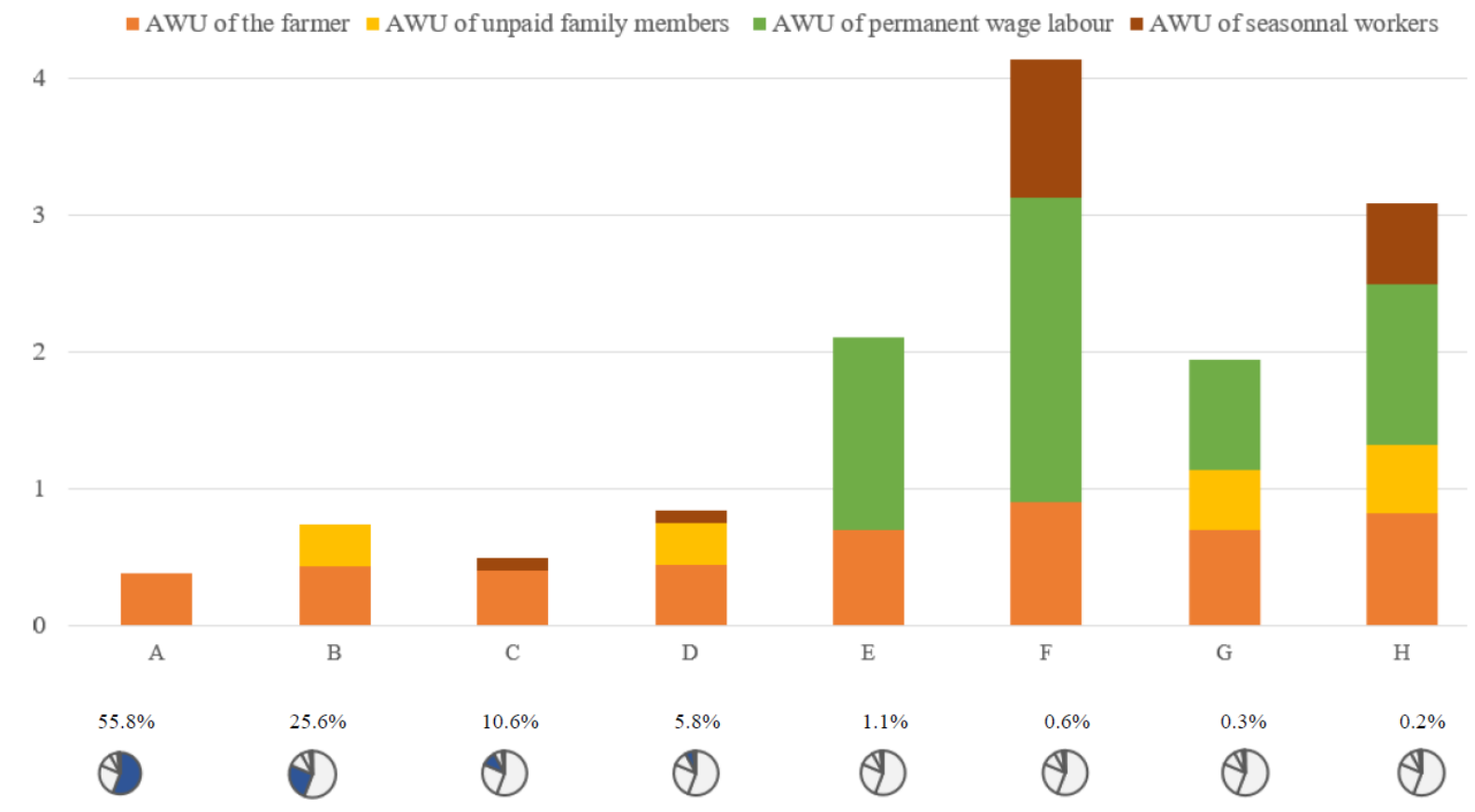

In 56 per cent of small French farms, the farmer worked alone on the farm, without any additional workforce (labour regime A); in 26 per cent of them, the farmer worked with unpaid family members only (labour regime B); in 11 per cent of them, the farmer worked with seasonal workers only (labour regime $\mathrm{C}$ ); in 6 per cent of them, the farmer worked with unpaid family members and seasonal workers (labour regime D).

It is only in the last four labour regimes $(\mathrm{E}),(\mathrm{F}),(\mathrm{G}),(\mathrm{H})$, representing 2 per cent of small French farms, that small farms had permanent paid labour. In these labour regimes, the average of agricultural work units per farm was by far the highest.

\section{What were the characteristics of labour-intensive small farms?}

Small farms in labour regimes $(\mathrm{E}),(\mathrm{F}),(\mathrm{G})$ and $(\mathrm{H})$ exceeded almost two full-time equivalents, mostly because of their main orientation towards market gardening which is the most labour- 
intensive production per hectare of UAA. Farmers on labour-intensive small farms had a high level of education and some of them were newcomers to agriculture (setting up after a professional reconversion without any agricultural education).

They also had diversification activities (processing, agritourism, leisure activities for example), sold part of their production in short distribution channels and/or produced under organic farming label standards. These labour-intensive activities can be developed because there is labour available on the farm, but also because the value added per hectare is high enough for small farms to afford hiring additional paid labour and bearing the associated costs (recruitment costs, supervision costs). Facilitating access to investment in high value-added activities can be a way to retain labour or even encourage the hiring of paid labour on small farms.

Among these labour-intensive regimes, we observe a concentration of pluriactive households in labour regimes (E) and (F). Spouses worked outside of the farm. This can probably be explained by their proximity to the job market because these farms were over-represented in urban areas (defined according to the number of jobs in the area and to 'home-to-work' commuting). Moreover, and due to their high level of education, it is likely that their expected remuneration for off-farm employment exceeded the cost of hiring paid labour. While a few farmers kept only supervisory tasks, most still worked on the farm, half time on average. Household pluriactivity in small farms is not always a survival strategy, and paid labour can replace that of unpaid family members (including the farmer himself). These cases show that some pluriactive farmers may seek to maintain a significant agricultural activity on the farm.

Small holdings in labour regimes $(\mathrm{G})$ and $(\mathrm{H})$ were over-represented in mountainous and isolated rural areas. The job market can be too remote or unsuitable for the spouse who mostly worked on the farm. Employer's alliances provide opportunities for job-sharing among farmers. They were particularly concentrated on the farms of labour regimes $(\mathrm{G})$ and $(\mathrm{H})$.

\section{Small farms with less than one full-time equivalent on the farm: what were they?}

In small farms belonging to labour regimes (A), (B), (C) and (D), the average worktime of the farmer was less than half time on the farm. There were no permanent paid workers and few of them had value-added activities. Farmers were also five years older than average and had a lower level of education than those in labour-intensive small farms.

In contrast to those in labour regimes (A) and (C), small farms in labour regimes (B) and (D) had unpaid family work. These farms were largely run by women who were on average the oldest of the whole population, settled at an advanced age and without any initial education in agriculture. They were assisted by their retired spouse, from whom they most certainly inherited the managing of the farm. In France, there is a system of transfer of the holding between spouses when the farmer retires that offers retirement benefits. This transmission system has been used widely to transfer the farm to younger wives. 
There is also a government scheme which is an employment-friendly support but it is little used by old farmers in small farms. The farmer receives a subsidy to cover a significant part of a young worker's wage costs and when he retires, he can then transfer his/her business to the paid worker.

In labour regimes (A) and (C) without any unpaid family workforce, the proportion of part-time farmers was high. The size of the farm did not always allow the farmer to devote all his/her time to farm work. In labour regime (A), the proportion of retired farmers was also high. In France, it is possible to combine retirement with small-scale farming if it is limited to a socalled subsistence plot providing a 'necessary farming activity'. For many of the retired farmers on small farms, farming is an indispensable complement to an agricultural pension that is too low to provide an adequate income.

\section{Box 1: Small farms managed by Farm Work Companies}

In some cases, contracts with Farm Work Companies (FWCs) can play an important role in carrying out farming work. We have identified those where FWC work is equal to or greater than the workforce of the manager.

They represented 0.3 per cent of small French farms $(0.8$ per cent in the whole farm population) and were mainly specialised in field crops and viticulture. The FWCs worked on average 0.3 AWUs in farms where the total agricultural workforce averaged 0.6 AWUs.

This type of small farm was mostly run by part-time farmers, who can be considered as hobby farmers (i.e. farmers working on farms with no need to generate an agricultural income). Surprisingly, however, a high proportion of this type of small farm was found in labour regimes $(\mathrm{E})$ and $(\mathrm{F})$. We thought that we would find this model of associated paid labour force and FWCs in larger farms, but it shows that distant management of a productive heritage also exists in small farms. More generally and at the level of all French farms, recent studies show an upward trend in the number of farms with labour outsourcing (Forget, 2019).

\section{What about public support measures for employment on small farms?}

In France, the CAP 2014-2020 with the convergence of direct payments and the redistributive payment from the first pillar is becoming more favourable to small farms, but the total impact on employment is expected to be modest (Forget et al., 2019). A distribution of aid per agricultural work unit instead of per hectare could be a more effective incentive for employment (salaried or not) and more specifically for employment on small farms. Without concluding specifically on small farms, the models carried out at French and European scales show that a distribution of aid according to employment could curb the erosion of agricultural labour. They conclude that the levers for preserving employment probably do not lie in the first pillar of the CAP (Forget et al., 2019). 
The second pillar of the CAP can co-finance value-added projects and indirectly support employment (paid and unpaid), as we have seen for labour-intensive small farms. Aid for investment in agrotourism, processing or more broadly in social farming or health therapy like in small Austrian farms, can be granted. However, it may represent a high administrative and financial burden for small farms with low cash flow. Finally, it is not uncommon for calls for tenders to specify a minimum amount of investment to be made on a project, which often imposes a minimum farm size. Specific investment support mechanisms comparable to the current Small Farmers Scheme in the first pillar of the CAP could be proposed. Small farmers would then benefit from low financial support adapted to their lower investment needs and lighter in administrative terms.

It should also be added that many career changes have recently taken place among highly qualified farmers who settle late and on very small plots, or even micro-farms specialising in market gardening. They may have additional workforce to supplement their own labour, improve or acquire agricultural technical skills that they may not have.

Supports for young farmers targets farmers under 40, excluding many of these newcomers. The age limit for this aid could be slightly increased or specific support could be introduced for farmers who set up later. While the setting up measure of young farmers is an important issue in France, countries like Germany, Denmark and the Netherlands have chosen not to implement it in the 2014-2020 programming period even though they also have generational renewal problems.

Ireland considers that part of the problem of generational renewal is that older farmers do not retire due to loss of status, social exclusion, loss of income, poor quality of pensions (Schuh et al., 2019). While in Germany farmers have to relinquish their farms to receive their retirement pension, as we have seen in France, some farmers supplement a too low pension by keeping a subsistence plot. A re-evaluation of agricultural pensions as the one voted for in France in June 2020, combined with setting up measure(s) that take into account late setting up could help young farmers and newcomers.

National French policy can grant farmers exemptions from employer contributions when hiring casual workers. Exemptions extended to permanent workers could be particularly relevant for small farms. However, today, this type of contribution exemption for permanent contracts is only granted to employer alliances. Only 0.4 per cent of small French farms with paid worker(s) are members of an employers' alliance. Their labour needs may be too low compared to other farms and require more members in the employers' alliance. In order to limit coordination difficulties, small farms may not be involved. Local councils, among others, finance the creation and development of employers' alliances. In order to tackle job insecurity, they may ask for a better inclusion of small structures with very partial jobs into employers' alliances.

The creation of a register of agricultural jobs, supplied by farmers, as recommended by Schuh et al. (2019) for Romania, or as the French 'arms for your plate' platform developed during the Covid-19 crisis (but specific to agricultural labour force) could help to better identify the labour 
needs of farms, including those of small farms. It could improve their involvement in the development of existing alliances, or even in the creation of employers' alliances. In addition to employers' alliances, this register would also be useful for farmers who limit the size of their holdings because they do not know how to find additional labour.

Some of the small farms are labour-intensive. They share characteristics that are strongly in line with the new expectations of citizens and consumers (local agriculture, official signs identifying quality and origin for example) that could enable them to play a more important role in the agricultural sector in the future. Targeted public policies, such as those proposed, are nevertheless necessary to facilitate the emergence of small labour-intensive farms and to encourage employment in those that could become labour-intensive.

\section{Acknowledgements}

This work was supported by Agropolis Foundation and Cariplo Foundation. Data have been made available by the Office of Statistics and Forecasting (SSP) via the Secure Access Center Distant (CASD).

\section{Further Reading}

- Benjamin, C., Corsi A. and Guyomard H. (1996). Modelling labour decisions of French agricultural households. Applied Economics, 28(12): 1577-1589.

- Birol, E., Smale M. and Gyoval A. (2006). Using a choice experiment to estimate farmers' valuation of agrobiodiversity on Hungarian small farms. Environmental \& Resource Economics, 34(4): 439-469.

- Davidova, S. (2014). Small and semi-subsistence farms in the EU: Significance and development paths. EuroChoices 13(1): 5-9.

- Forget, V., Depeyrot J.-N., Mahé M., Midler E., Hugonnet M., Beaujeu R., Grandjean A. and Hérault B. (2019). Actif'Agri. Transformations des emplois et des activités en agriculture, Centre d'études et de prospective, Ministère de l'agriculture et de l'alimentation, la Documentation française, Paris.

- Hazell, P.B.R. (2005). Is there a future for small farms? Agricultural Economics, 32(1): 93-101.

- Lécole, P. (2017). Les petites exploitations agricoles françaises. Economies et finances. Montpellier SupAgro, Ph.D 2017 https://www.supagro.fr/theses/extranet/170036_Lecole.pdf

- Muller, P. (1984). Le technocrate et le paysan. Paris, Les Editions ouvrières 1984, 173p. 
- Salvioni, C., Papadopoulou, E. and Dos Santos, M. (2014). Small farm survival in Greece, Italy and Portugal. Eurochoices, 13(1): 52-57.

- Schuh, B. et al., (2019). Research for AGRI Committee - The EU farming employment: current challenges and future prospects, European Parliament, Policy Department for Structural and Cohesion Policies, Brussels. https://www.europarl.europa.eu/RegData/etudes/STUD/2019/629209/IPOL_STU(2019)62920 9_EN.pdf

- Winter, M., Lobley, M., Chiswell, H., Howe, K., Wilkinson, T. and Wilson, P. (2016). Is there a future for the small family farm in the UK? Report to The Prince's Countryside Fund. London, Prince's Countryside Fund (Politics).

- Zasada, I. (2011). Multifunctional peri-urban agriculture - A review of societal demands and the provision of goods and services by farming. Land Use Policy, 28(4): 639-648.

\section{Summary}

The contributions of small farms to the environment or employment are increasingly recognised. Yet small farm employment receives little support from public policies. Can small farms provide employment opportunities in the agricultural sector? The objective of this work is to contribute to reflections on a better adaptation of public support to the heterogeneity of the contributions of small farms to employment. This article focuses on the example of France, using the 2010 agricultural census data. It proposes a typology of workforce patterns in French small farms.

In 2010, labour-intensive small farms with paid worker(s) accounted for just over 2 per cent of small farms in France. They were managed by trained farmers, sometimes newcomers to agriculture, and had high value-added activities like agrotourism, short distribution channels and/or organic farming production. We conclude with recommendations for European and national public policies aimed at encouraging the maintenance and/or creation of employment on small farms. They include, for example, specific support for small farms, adapted to their lower investment needs and a lighter administrative burden to enable them to develop labourintensive projects; or a better integration of small farms into employers' alliances. 